Polymer Journal, Vol. 39, No. 11, pp. 1150-1156 (2007)

(C)2007 The Society of Polymer Science, Japan

\title{
Synthesis of Hyperbranched Polymer with Degree of Branching of Approximately $100 \%$ by Polycondensation of 2-(4-Phenoxyphenoxy)fluorenone
}

\author{
Shunji Kono, ${ }^{1,2}$ Warapon SinANANwanich, ${ }^{1}$ Yuji SHIBASAKI, ${ }^{1}$ \\ Shinji ANDO, ${ }^{1}$ and Mitsuru UEDA ${ }^{1, \uparrow}$ \\ ${ }^{1}$ Department of Organic \& Polymeric Materials, Graduate School of Science \& Engineering, \\ Tokyo Institute of Technology, 2-12-1-H120, O-okayama, Meguro-ku, Tokyo 152-8552, Japan \\ ${ }^{2}$ Advanced Materials Laboratory, Department of Chemical Engineering, Tsinghua University, Beijing 100084, P.R. China
}

(Received June 27, 2007; Accepted July 27, 2007; Published September 14, 2007)

\begin{abstract}
An approximately $100 \%$ branched hyperbranched polymer was successfully prepared using 2-(4phenoxyphenoxy)fluorenone as a monomer in an acidic medium. The kinetics of the model reaction between 9-fluorenone and anisole was investigated. The reaction obeyed the second-order kinetics, indicating that the first reaction, i.e., the formation of the intermediate from 9-fluorenone and anisole, is considerably slower than the second one, i.e., the reaction of the intermediate with anisole. Based on this finding, a new monomer expected to produce a $100 \%$ branched hyperbranched polymer, 2-(4-phenoxyphenoxy)fluorenone, was designed and prepared. The polymer thus obtained was characterized by FT/IR and ${ }^{13} \mathrm{C}$ NMR spectroscopy, which confirmed that the polymer was an almost $100 \%$ branched hyperbranched polymer. [doi:10.1295/polymj.PJ2007090]

KEY WORDS Hyperbranched Polymer / Degree of Branching / Polycondensation / Kinetics / Fluorenone / Anisole /
\end{abstract}

Hyperbranched polymers have attracted considerable attention owing to their unique properties such as an intrinsic globular structure, low viscosity, high solubility, and a large number of terminal functional groups. There are many reports on the synthesis and characterization of hyperbranched polymers and their various applications such as those in blended components, photosensitive materials, nonlinear optics, and catalysts. ${ }^{1-8}$ Hyperbranched polymers are generally characterized by a degree of branching (DB) that is theoretically approximately $50 \%$ for a polymer derived from an $\mathrm{AB}_{2}$ monomer; this value is assumed on the basis of the equal reactivity of the $\mathrm{B}$ functional groups of the $\mathrm{AB}_{2}$ monomer. ${ }^{9}$ The approaches reported to enhance the DB include slow addition, ${ }^{10}$ polymerization in the presence of polyfunctional core molecules, ${ }^{11}$ use of polyfunctional $\mathrm{AB}_{\mathrm{x}}$ monomers, ${ }^{12}$ and post-synthetic modification. ${ }^{13}$ Although these methods improve the DB, they do not result in a $100 \%$ DB. To obtain hyperbranched polymers with a $100 \% \mathrm{DB}$, the first reaction step of an $\mathrm{AB}_{2}$ monomer should activate the second reaction. ${ }^{14}$ Voit et al. have reported the synthesis of a hyperbranched polymer with a $100 \% \mathrm{DB}$ by the polymerization of an $\mathrm{AB}_{2}$ type monomer in "criss-cross" cycloaddition with the maleimide group as the A functional group and azine groups as the two B groups. ${ }^{15}$ Recently, Smets et al. have reported that the acid-catalyzed polycondensation of isatins or acenaphthenones with aromatic compounds yielded hyperbranched polymers with a $100 \%$ DB. ${ }^{16,17}$ These reports prompted us to synthesize a hyperbranched polymer with an approximately $100 \%$ DB from a common ketone compound.

Ordinary ketones such as fluorenone show a poor ability to undergo diarylation; $\mathrm{HCl}$ catalyzes the condensation of fluorenone with phenol to afford the corresponding diarylated compound in a $46 \%$ yield in $2 \mathrm{~d} .{ }^{18}$ Yamada et al. demonstrated that the diarylation of fluorenone effectively proceeds when 3-mercaptopropionic acid (MPA) is added to the reaction mixture at $65^{\circ} \mathrm{C} .{ }^{19}$

Therefore, we expected that the diarylation utilizing an acid with MPA could apply to the synthesis of $100 \%$ branched hyperbranched polymer.

In this paper, we present the synthesis of a hyperbranched polymer with an approximately $100 \%$ DB by the polycondensation of an $\mathrm{AB}_{2}$ monomer, 2-(4phenoxyphenoxy)fluorenone. The model reaction of 9-fluorenone (1) with anisole (2) in the presence of a catalyst in an organic acid is investigated to elucidate the reactivity of the second $\mathrm{B} v s$. the first $\mathrm{B}$ of the $\mathrm{AB}_{2}$ monomer.

\section{EXPERIMENTAL}

\section{Materials}

All chemicals were used as received unless otherwise noted.

${ }^{\dagger}$ To whom correspondence should be addressed (Tel: +81-3-5734-2127, Fax: +81-3-5734-2127, E-mail: ueda.m.ad@m.titech.ac.jp). 
Synthesis of 9,9'-bis(4-methoxyphenyl)fluorene and measurements of reaction progress by ${ }^{1} H$ NMR spectroscopy

A solution of $5 \mathrm{wt} \% 3$-mercaptopropionic acid $(0.0177 \mathrm{~g}, 0.166 \mathrm{mmol})$ in trifluoroacetic acid $(0.23$ $\mathrm{mL})$ was added to a solution of $\mathbf{1}(1.00 \mathrm{~g}, 5.55 \mathrm{mmol})$, dodecane $(0.047 \mathrm{~g}, 0.278 \mathrm{mmol})$ and $2(0.96 \mathrm{~g}, 8.84$ $\mathrm{mmol})$ in trifluoroacetic acid $(3.7 \mathrm{~mL})$. The solution was stirred at $60^{\circ} \mathrm{C}$ under nitrogen atmosphere, and then the reaction was monitored by successive measurements of the ${ }^{1} \mathrm{H}$ NMR spectra of a drop of the reaction solution into chloroform- $d$ at different times. After $20 \mathrm{~h}$ reaction, the reaction solution was poured into water $(300 \mathrm{~mL})$. The precipitate was filtered, washed with water, and dried in vacuo at $100^{\circ} \mathrm{C}$ for $12 \mathrm{~h}$. The product was recrystallized from ethanol to give white needles. The yield was $0.69 \mathrm{~g}(41 \%)$. Mp. $137-138^{\circ} \mathrm{C}\left(\mathrm{lit}^{3} 126^{\circ} \mathrm{C}\right)$. IR $\left(\mathrm{KBr}, v, \mathrm{~cm}^{-1}\right): 3035$ (Ar), $2834\left(\mathrm{O}^{-\mathrm{CH}_{3}}\right), 1600(\mathrm{Ar}), 1500(\mathrm{Ar}), 1180(\mathrm{O}-$ Ar), $1033\left(\mathrm{O}-\mathrm{CH}_{3}\right),{ }^{1} \mathrm{H}$ NMR $\left(\mathrm{CDCl}_{3}, \delta, \mathrm{ppm}\right): 3.74$ (s, $\left.6 \mathrm{H}, \mathrm{OC}_{3}\right), 6.75$ (d, 4H, $\left.\underline{\mathrm{Ar}}\right), 7.11(\mathrm{~d}, 4 \mathrm{H}, \underline{\mathrm{ArH}})$, 7.22-7.41 (m, 6H, $\underline{\mathrm{ArH}}), 7.75$ (d, 2H, $\underline{\mathrm{ArH}}) .{ }^{13} \mathrm{C} \mathrm{NMR}$ $\left(\mathrm{CDCl}_{3}, \delta, \mathrm{ppm}\right): 55.14,64.11,113.48,120.09$, $125.97,127.28,127.65,129.12,138.08,139.91$, 151.80, 158.23. Anal. Calcd. for $\mathrm{C}_{27} \mathrm{H}_{22} \mathrm{O}_{2}$ : C, 85.69; H, 5.86; Found C, 85.46; H, 5.91.

\section{Synthesis of 9-(4-methoxyphenyl)-9H-fluoren-9-ol (4)}

The Grignard reagent was prepared from magnesium powders $(270 \mathrm{mg}, 11.1 \mathrm{mmol})$ in dry tetrahydrofuran $(6 \mathrm{~mL})$ and 4-bromoanisole $(2.07 \mathrm{~g}, 11.0 \mathrm{mmol})$ in dry tetrahydrofuran $(10 \mathrm{~mL})$ at $80^{\circ} \mathrm{C}$ for $1 \mathrm{~h} .9$ Fluorenone $(1.00 \mathrm{~g}, 5.54 \mathrm{mmol})$ was added to the cooled Grignard solution. The mixture was refluxed for $6 \mathrm{~h}$. The reaction mixture was neutralized with a saturated $\mathrm{NH}_{4} \mathrm{Cl}$ solution, extracted with diethyl ether, washed with brine, dried over $\mathrm{MgSO}_{4}$. Purification was performed by silica gel column chromatography $($ EtOAc/Hexane $=1 / 9)$ to give a title product $(1.40 \mathrm{~g}, 87 \%) .{ }^{1} \mathrm{H}$ NMR $\left(\mathrm{CDCl}_{3}, \delta, \mathrm{ppm}\right): 2.40$ (s, $1 \mathrm{H}, \underline{\mathrm{OH}}), 3.76\left(\mathrm{~s}, 3 \mathrm{H}, \mathrm{OCH}_{3}\right), 6.79(\mathrm{~d}, 2 \mathrm{H}, \underline{\mathrm{ArH}})$, 7.20-7.40 (m, 8H, ArH), 7.65 (d, 2H, ArH). ${ }^{13} \mathrm{C}$ NMR $\left(\mathrm{CDCl}_{3}, \delta, \mathrm{ppm}\right): 55.62,83.80,114.00,120.49$, $125.12,127.02,128.85,129.45,135.65,139.88$, $150.91,159.22$.

\section{Synthesis of 2-(4-phenoxyphenoxy)fluorene}

The mixture of 4-phenoxyphenol $(8.08 \mathrm{~g}, 43.4$ $\mathrm{mmol})$ and potassium carbonate $(5.08 \mathrm{~g}, 36.8 \mathrm{mmol})$ in toluene $(30 \mathrm{~mL})$ was heated at $140{ }^{\circ} \mathrm{C}$ for $2 \mathrm{~h}$ to remove water with a dean-stark apparatus. After the formation of the potassium salt, toluene was removed by heating at $150{ }^{\circ} \mathrm{C}$. The residue was further dried under reduced pressure at $100^{\circ} \mathrm{C}$, followed by cooling down to room temperature. To this salt were added bromo- fluorene $(3.00 \mathrm{~g}, 12.3 \mathrm{mmol})$, copper $(0.039 \mathrm{~g}, 0.62$ $\mathrm{mmol})$ and quinoline $(1.59 \mathrm{~g}, 12.3 \mathrm{mmol})$, followed by heating the mixture at $190^{\circ} \mathrm{C}$ for $20 \mathrm{~h}$ under nitrogen atmosphere. After cooling the mixture to room temperature, it was poured into a sodium hydroxide aqueous solution $(2 \mathrm{~mol} / \mathrm{L})$. The solution was extracted with dichloromethane, and then organic layer was evaporated. The residue was purified by silica gel column chromatography (toluene/hexane 3:7 in volume). White crystals were obtained after drying at $80^{\circ} \mathrm{C}$ in vacuo. The yield was $1.81 \mathrm{~g}(42 \%)$. Mp. 143$144^{\circ} \mathrm{C}$; IR (KBr, $v, \mathrm{~cm}^{-1}$ ): 3039, 1592, 1492 (Ar), 1220 (O-Ar), ${ }^{1} \mathrm{H}$ NMR $\left(\mathrm{CDCl}_{3}, \delta, \mathrm{ppm}\right): 3.87$ (s, $\left.2 \mathrm{H}, \mathrm{CH}_{2}\right), 6.98-7.11(\mathrm{~m}, 8 \mathrm{H}, \underline{\operatorname{ArH}}), 7.18(\mathrm{~s}, 1 \mathrm{H}$, $\underline{\mathrm{ArH}}), 7.27(1 \mathrm{H}, \underline{\mathrm{ArH}}), 7.30-7.39(\mathrm{~m}, 3 \mathrm{H}, \underline{\operatorname{ArH}})$, $7.52(\mathrm{~d}, 1 \mathrm{H}, \underline{\mathrm{ArH}}), 7.68-7.75(\mathrm{~d}, 2 \mathrm{H}, \mathrm{ArH})$. Anal. Calcd. for $\mathrm{C}_{25} \mathrm{H}_{18} \mathrm{O}_{2}$ : C, 85.69; H, 5.18; Found C, 85.64; H, 5.26.

\section{Synthesis of 2-(4-phenoxyphenoxy)fluorenone (5)}

2-(4-Phenoxyphenoxy)fluorene $(4.31 \mathrm{~g}, 12.3 \mathrm{mmol})$ and $40 \mathrm{wt} \%$ tetrabuthylammonium hydroxide $(0.16 \mathrm{~g}$, $0.615 \mathrm{mmol}$ ) in methanol was dissolved in pyridine $(25 \mathrm{~mL})$. The solution was heated at $60^{\circ} \mathrm{C}$ for $20 \mathrm{~h}$ under the air, and then was acidified with glacial acetic acid. The solution was evaporated under reduced pressure, and the residue was poured into the water. The precipitate was purified by silica gel column chromatography (toluene). The product was recrystallized from hexane to give faint yellow needles. The yield was $3.30 \mathrm{~g}(74 \%)$. Mp. $88-89^{\circ} \mathrm{C}$; IR $\left(\mathrm{KBr}, v, \mathrm{~cm}^{-1}\right)$ : 3062 (Ar), 1708 (C=O), 1600, 1484 (Ar), 1222 (OAr). ${ }^{1} \mathrm{H}$ NMR (DMSO-d, $\left.\delta, \mathrm{ppm}\right): 7.00-7.18(\mathrm{~m}$, $8 \mathrm{H}, \operatorname{ArH}), 7.21(\mathrm{~d}, 1 \mathrm{H}, \underline{\operatorname{ArH}}), 7.31(\mathrm{t}, 1 \mathrm{H}, \underline{\operatorname{ArH}})$, $7.40(\mathrm{t}, 2 \mathrm{H}, \underline{\operatorname{ArH}}), 7.53-7.60(\mathrm{~m}, 2 \mathrm{H}, \underline{\operatorname{ArH}}), 7.71(\mathrm{~d}$, $1 \mathrm{H}, \underline{\operatorname{ArH}}), 7.75(\mathrm{~d}, 1 \mathrm{H}, \underline{\operatorname{ArH}}) .{ }^{13} \mathrm{C}$ NMR (DMSO-d, $\delta, \mathrm{ppm}): 112.87,118.21,120.25,120.59,120.89$, $122.55,123.22,123.75,123.87,128.54,129.86$, $133.36,135.14,135.35,138.34,143.70,151.18$, 152.82, 156.83, 158.58, 192.17. Anal. Calcd. for $\mathrm{C}_{25} \mathrm{H}_{16} \mathrm{O}_{3}: \mathrm{C}, 82.40 ; \mathrm{H}, 4.43$; Found C, 82.25; H, 4.56.

Synthesis of poly[2-(4-phenoxyphenoxy)fluorenone] (6)

3-Mercaptopropionic acid $(0.00291 \mathrm{~g}, 27.5 \mu \mathrm{mol})$ in dichloromethane $(0.22 \mathrm{~mL})$ was added to a solution of 2-(4-phenoxyphenoxy)fluorenone $(0.20 \mathrm{~g}, 0.549$ $\mathrm{mmol})$ and methanesulfonic acid $(0.59 \mathrm{~mL})$ in dichloromethane $(0.53 \mathrm{~mL})$. The solution was heated at $40{ }^{\circ} \mathrm{C}$ for $45 \mathrm{~min}$ under a nitrogen atmosphere. The solution was poured into sodium hydrogen carbonate aqueous solution $(50 \mathrm{~mL})$. After filtration, the solid was washed with water $(50 \mathrm{~mL})$, methanol $(50$ $\mathrm{mL})$ and acetone $(50 \mathrm{~mL})$, and then slightly yellowish polymer was obtained $(0.16 \mathrm{~g}, 81 \%)$. IR $(\mathrm{KBr}, v$, 


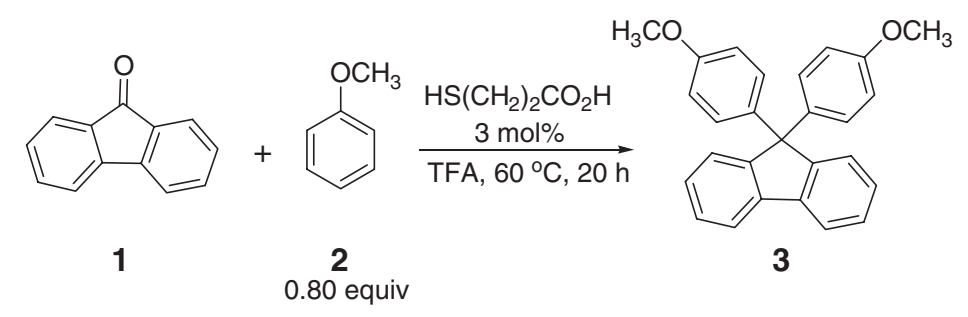

Scheme 1.

$\left.\mathrm{cm}^{-1}\right)$ : $1716(\mathrm{C}=\mathrm{O}), 1604,1492(\mathrm{Ar}), 1218(\mathrm{O}-\mathrm{Ar})$. ${ }^{1} \mathrm{H}$ NMR $\left(\mathrm{CDCl}_{3}, \delta, \mathrm{ppm}\right)$ : 6.50-7.90 (broad, $\left.\mathrm{ArH}\right)$. ${ }^{13} \mathrm{C}$ NMR $\left(\mathrm{CDCl}_{3}, \delta, \mathrm{ppm}\right): 64.32,64.98,113.73$, $117.66,117.97,118.21,119.84,120.05,120.10$, $120.38,120.67,120.88,121.47,122.99,123.52$, $124.40,127.62,128.30,129.30,129.41,129.70$, $134.27,134.88,135.96,138.73,140.24,144.31$, $151.67,153.11,153.39,156.41,159.19,193.41$. $M_{\mathrm{n}}=7300 \mathrm{~g} / \mathrm{mol}, M_{\mathrm{w}} / M_{\mathrm{n}}=4.4\left(\mathrm{GPC}\right.$ in $\left.\mathrm{CHCl}_{3}\right)$.

\section{Measurements}

The IR spectra were obtained using a Horiba FT210 spectrophotometer. The NMR spectra were recorded on a JEOL JNM-AL400 (400 MHz) spectrometer. Number- and weight-average molecular weights $\left(M_{\mathrm{n}}\right.$ and $\left.M_{\mathrm{w}}\right)$ were determined by a gel permeation chromatograph (GPC) on a Jasco GULLIVER 1500 system equipped with a polystyrene gel column (Plgel $5 \mu \mathrm{m}$ MIXED-C) eluted with chloroform at a flow rate of $1.0 \mathrm{~mL} \mathrm{~min}^{-1}$ calibrated by standard polystyrene samples.

\section{RESULTS AND DISCUSSION}

\section{Model reaction between 1 and $\mathbf{2}$}

As described in the introduction, the diarylation of activated carbonyl compounds such as isatins proceeds in the presence of an acid. Yamada et al. demonstrated that the diarylation of fluorenone effectively proceeds when 3-mercaptopropionic acid (MPA) is added to the reaction mixture at $65^{\circ} \mathrm{C} .{ }^{19}$ Thus, we first investigated the model reaction between $\mathbf{1}$ and $\mathbf{2}$ in the presence of MPA in sulfuric acid. The reaction proceeded, but the solution was heterogeneous, which might have inhibited the polymerization. Hence, methanesulfonic acid was used instead of sulfuric acid. Because the reaction proceeded in a homogeneous solution, it terminated within a few minutes at $20^{\circ} \mathrm{C}$. In order to plotting the time-conversion relationship for this reaction, the same condensation was performed in the presence of trifluoroacetic acid (TFA). The reaction between $\mathbf{1}$ and $\mathbf{2}$ was conducted at $60^{\circ} \mathrm{C}$ for $20 \mathrm{~h}$ in the presence of $3 \mathrm{~mol} \%$ MPA (Scheme 1). The ${ }^{1} \mathrm{H}$ NMR spectrum of the reaction mixture revealed the presence of the expected diary-



Figure 1. ${ }^{1} \mathrm{H}$ NMR spectra of the reaction mixture at (A) 0 , (B) 2.5 , and (C) $20 \mathrm{~h}$, (D) the isolated compound 3, and (E) 4 .

lated compound, 9,9-bis(4-methoxyphenyl)fluorene (3) with the unconverted $\mathbf{1}$, indicating that the condensation was completed under this condition.

The reaction was then monitored by periodically measuring the ${ }^{1} \mathrm{H}$ NMR spectra of a drop of the reaction solution at different times at $25^{\circ} \mathrm{C}$. Figure 1 shows the ${ }^{1} \mathrm{H}$ NMR spectra of the reaction mixture and 3 and 4 . After $2.5 \mathrm{~h}$, signals assignable to 3 are observed at 7.76, 7.10-7.40, 6.82, and 3.85 ppm in addition to the signals of $\mathbf{1}$ and $\mathbf{2}$. It is noteworthy that no other signals are observed in this spectrum, suggesting that the condensation of $\mathbf{1}$ with $\mathbf{2}$ proceeds quickly via the intermediate $\mathbf{4}$, whose reactivity is significantly higher than that of the starting material $\mathbf{1}$. To confirm the formation of $\mathbf{4}$ during the reaction, a model compound 4 was prepared by the reaction between fluorenone and $p$-methoxyphenyl magnesium bromide, as shown in Scheme 2. ${ }^{20}$ The characteristic proton signal of the methoxy protons of $\mathbf{4}$ (in the presence of TFA) was observed at $3.66 \mathrm{ppm}$. No peak at 3.66 is observed in Figure 1, which means the reaction of $\mathbf{4}$ with $\mathbf{2}$ is very fast compared to that of $\mathbf{1}$ with $\mathbf{2}$. This result suggests that $\mathbf{4}$ reacts immediately with $\mathbf{2}$ in TFA. 


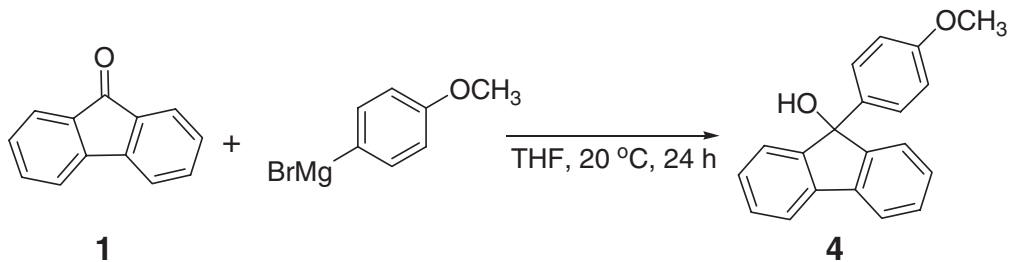

Scheme 2.

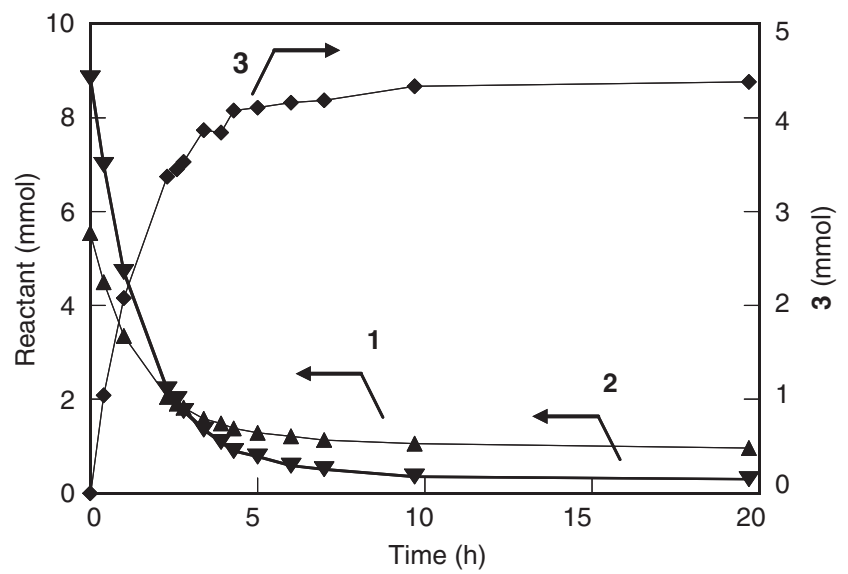

Figure 2. Relationship between the amounts of the reactants, i.e., $\mathbf{1}(\Delta)$ and $\mathbf{2}(\boldsymbol{\nabla})$, and the product $\mathbf{3}(\diamond)$ with the reaction time.

Figure 2 illustrates the changes in the consumption of $\mathbf{1}$ and $\mathbf{2}$ and the yield of $\mathbf{3}$ with the reaction time. The yield of $\mathbf{3}$ increases with a decrease in the concentrations of $\mathbf{1}$ and 2. This result has a complementary relationship, indicating that no side reaction occurred during the condensation. Consequently, the reaction rate constant of the second step, namely, $k_{2}$ is considerably greater than that of the first step, i.e., $k_{1}$.

To investigate the reaction mechanism in more detail, the kinetics was studied based on the following equations:

$$
\left\{\begin{array}{l}
\mathbf{1}+\mathbf{2} \stackrel{k_{1}}{\longrightarrow} \mathbf{I} \\
\mathbf{I}+\mathbf{2} \stackrel{k_{2}}{\longrightarrow} \mathbf{3}
\end{array}\right.
$$

where $\mathbf{I}$ is the intermediate

$$
\left\{\begin{array}{l}
-\mathrm{d}[\mathbf{2}] / \mathrm{dt}=k_{1}[\mathbf{1}][\mathbf{2}]+k_{2}[\mathbf{I}][\mathbf{2}] \\
-\mathrm{d}[\mathbf{1}] / \mathrm{dt}=k_{1}[\mathbf{1}][\mathbf{2}] \\
\mathrm{d}[\mathbf{I}] / \mathrm{dt}=k_{1}[\mathbf{1}][\mathbf{2}]-k_{2}[\mathbf{I}][\mathbf{2}] \\
\mathrm{d}[\mathbf{3}] / \mathrm{dt}=k_{2}[\mathbf{I}][\mathbf{2}]
\end{array}\right.
$$

If $k_{1} \ll k_{2}$, the amount of the intermediate $\mathbf{I}$ can be ignored in the steady state. Thus,

$$
\mathrm{d}[\mathbf{I}] / \mathrm{dt}=0
$$

From equations (3) and (5), the concentration of I can be expressed as follows:

$$
[\mathbf{I}]=k_{1} / k_{2}[\mathbf{1}]
$$

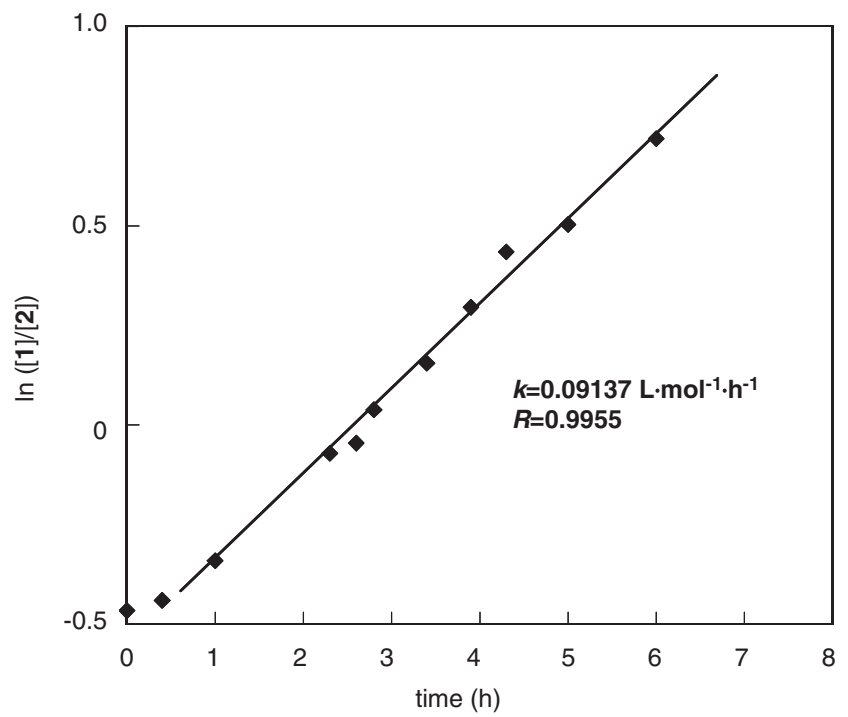

Figure 3. Second-order kinetic plot for the condensation of 1 with 2.

Equation (4) can then be expressed using (6) as

$$
\mathrm{d}[3] / \mathrm{dt}=k_{1}[1][2]
$$

The concentrations of $\mathbf{1}$ and $\mathbf{2}$ are given by

$$
[1]=[1]_{0}-[3] \text { and }[2]=[2]_{0}-2[3]
$$

Therefore, equation (7) is written as

$$
\mathrm{d}[\mathbf{3}] / \mathrm{dt}=k_{1}\left([\mathbf{2}]_{0}-2[\mathbf{3}]\right)\left([\mathbf{1}]_{0}-[\mathbf{3}]\right)
$$

This expression can be integrated under the conditions that $[3]=0$ at time $\mathrm{t}=0$

$$
\ln ([\mathbf{1}] /[\mathbf{2}])=\left(2[\mathbf{1}]_{0}-[\mathbf{2}]_{0}\right) k_{1} t+\ln \left([\mathbf{1}]_{0} /[\mathbf{2}]_{0}\right)
$$

Figure 3 shows a linear relationship between $\ln ([1] /[2])$ and the reaction time; the overall reaction rate $(k)$ and the correlation coefficient $(R)$ were estimated to be $0.0913 \mathrm{~L} \cdot \mathrm{mol}^{-1} \cdot \mathrm{h}^{-1}$ and 0.995 , respectively. These results indicate that the first reaction, i.e., the reaction between $\mathbf{1}$ and $\mathbf{2}$ is the rate-limiting step in this reaction.

Synthesis of monomer 2-(4-phenoxyphenoxy)fluorenone (5)

Based on the above findings, a new $\mathrm{AB}_{2}$ monomer 5 was designed and synthesized by the Ullmann reaction between 4-phenoxyphenol and 2-bromofluorene, 


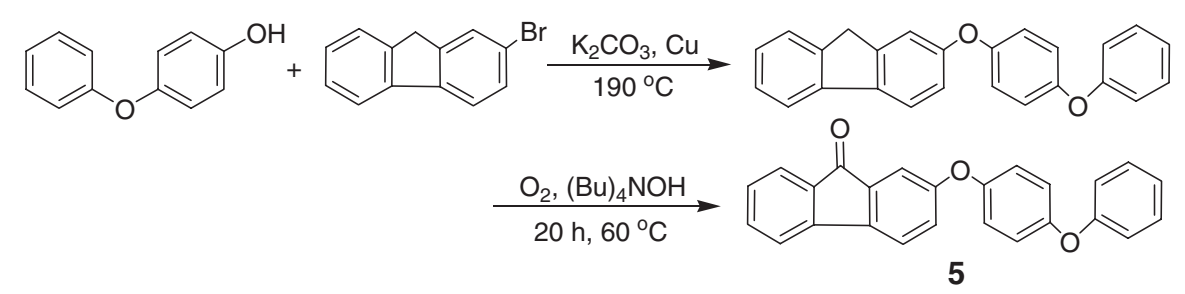

Scheme 3.
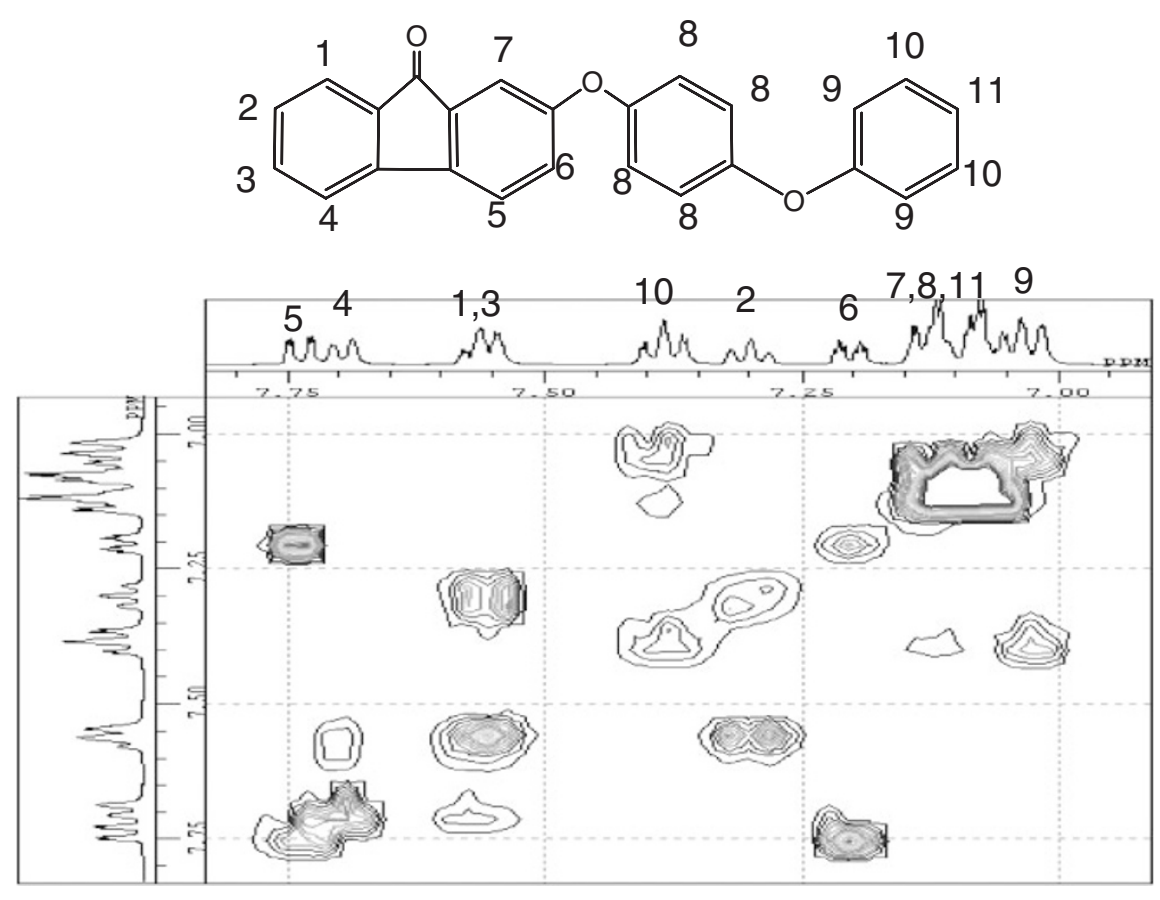

Figure 4. ${ }^{1} \mathrm{H}^{-1} \mathrm{H}$ COSY spectrum of 5 .

followed by oxidation in air in the presence of tetrabutylammonium hydroxide (Scheme 3). The structure of 5 was determined by FT/IR and NMR spectroscopy and elemental analysis. The IR spectrum of $\mathbf{5}$ showed characteristic absorptions corresponding to the carbonyl and the carbon-oxygen bond stretching at 1708 and $1222 \mathrm{~cm}^{-1}$, respectively. The ${ }^{1} \mathrm{H}$ NMR spectrum of 5 was measured, in which all the signals were well assigned. A complete assignment of the aromatic protons was performed by using the H-H COSY spectrum (Figure 4). The aromatic protons at positions 5 and 4 corresponds to the lowest $(7.75 \mathrm{ppm})$ and the second lowest $(7.71 \mathrm{ppm})$ downfield shifts, respectively. The doublet peaks at 7.75 and $7.71 \mathrm{ppm}$ correlate to the doublet-doublet signal at $7.21 \mathrm{ppm}$ and the multiplet peak at $7.55 \mathrm{ppm}$, respectively. Thus, the peaks at 7.21 and $7.55 \mathrm{ppm}$ are assigned to the aromatic protons at positions 6 and 3, respectively. On the other hand, the triplet peak at $7.31 \mathrm{ppm}$ correlates to two multiplet peaks at 7.55 and $7.58 \mathrm{ppm}$. Accordingly, the peak at 7.31 is assigned to the aromatic proton at position 2. The other signals are assigned in the same manner.

\section{Polycondensation of $\mathbf{5}$}

The self-polycondensation of $\mathbf{5}$ was carried out in the presence of MPA in methanesulfonic acid/dichloromethane (v/v, 1:1) at $40^{\circ} \mathrm{C}$, as described above; TFA also catalyzed the diarylation but was less effective than methanesulfonic acid. The polymerization proceeded in the homogeneous solution, resulting in an $81 \%$ yield of the hyperbranched polymer 6 . This polymer is soluble in THF, chloroform, and methylene chloride, and the number-average molecular weight and the polydispersity were $7.3 \times 10^{3} \mathrm{~g} \cdot \mathrm{mol}^{-1}$ and 4.4, respectively, as estimated by gel-permeation chromatography in chloroform calibrated with polystyrene standards.

\section{Characterization of polymer 6}

Because the polycondensation of $\mathrm{AB}_{2}$ monomers generally affords three types of structures-dendritic (D), linear (L), and terminal (T) units-as illustrated in Scheme 4, the structure of $\mathbf{6}$ was carefully identified by FT/IR and NMR spectroscopy. The FT/IR spectrum exhibited characteristic absorptions at 1716 and $1218 \mathrm{~cm}^{-1}$ due to the carbonyl and carbon-oxy- 


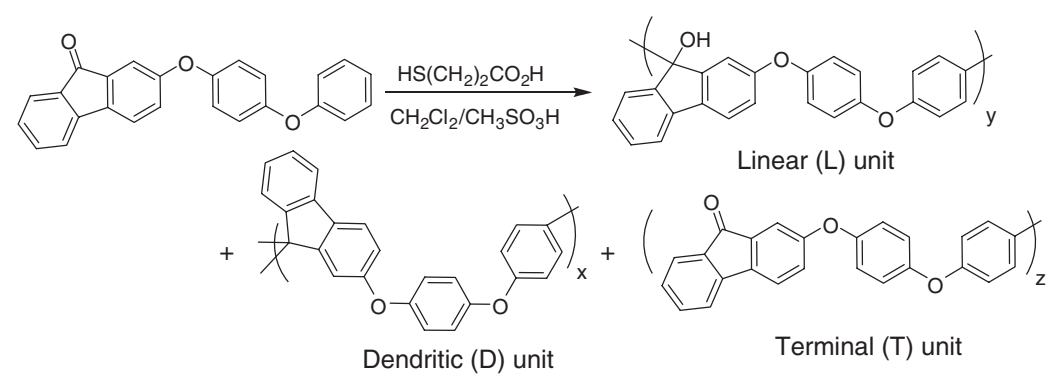

Scheme 4.

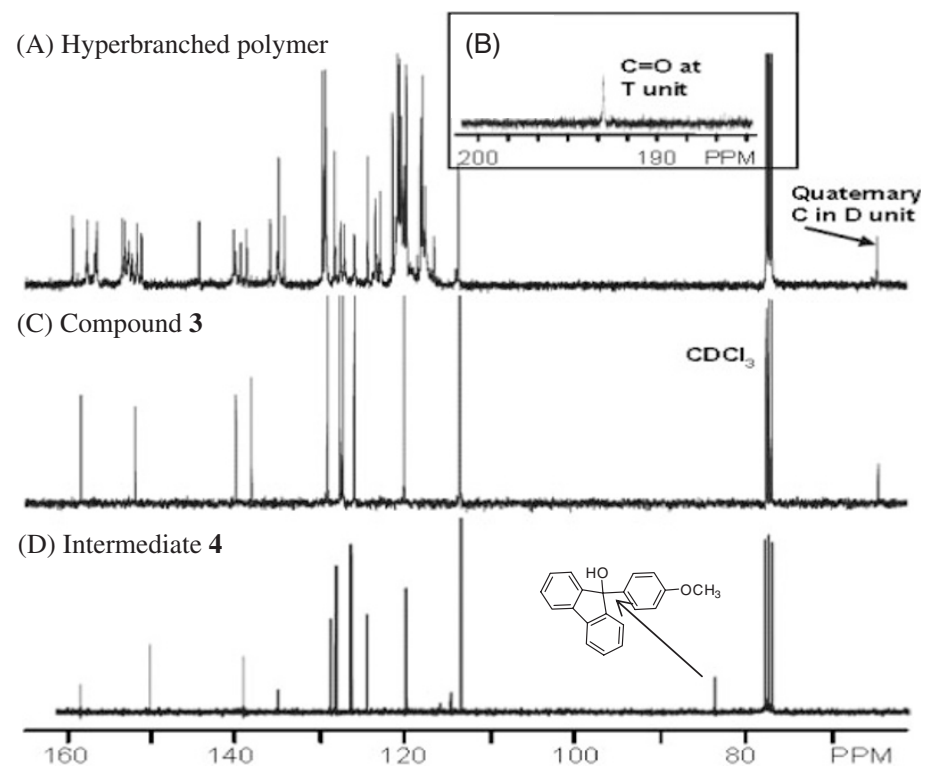

Figure 5. ${ }^{13} \mathrm{C}$ NMR spectra of (A) the hyperbranched polymer, (B) expanded field from 185-200 ppm, (C) model compound 3, and (D) intermediate 4.

gen bond stretching, respectively. The microstructure of 6 was investigated by ${ }^{13} \mathrm{C}$ NMR spectroscopy, and the results are shown in Figure 5. Two characteristic signals are observed at 193 and $64 \mathrm{ppm}$, which correspond to the carbonyl and quaternary carbons at the $\mathrm{T}$ and $\mathrm{D}$ units, respectively. In particular, the signal from the quaternary carbon appears separately, and there is no signal around $82 \mathrm{ppm}$, at which the tertiary carbon of $\mathbf{6}$ appears. This indicates that the resulting polymer is an approximately $100 \%$ hyperbranched polymer, as illustrated in Figure 6.

\section{CONCLUSION}

In conclusion, the model reaction between $\mathbf{1}$ and $\mathbf{2}$ in the presence of MPA in an organic acid produced a quantitative yield of $\mathbf{3}$, and the ${ }^{1} \mathrm{H}$ NMR spectra in the reaction mixture did not show the formation of the intermediate 4 during the course of the reaction. These results suggest that the second reaction step $\left(k_{2}\right)$ was faster than the first one $\left(k_{1}\right)$. The kinetics of the model reaction was studied. The reaction obeyed the secondorder kinetics, indicating that the first reaction, i.e.,



Figure 6. $100 \%$ branched hyperbranched polymer.

the formation of $\mathbf{4}$ from $\mathbf{1}$ and $\mathbf{2}$, was considerably slower than the second one, i.e., the reaction of $\mathbf{4}$ with 2. Based on these findings, the new $\mathrm{AB}_{2}$ monomer 5 was designed and prepared from 4-phenoxyphenol in two steps. The acid-catalyzed polycondensation of $\mathbf{5}$ yielded the hyperbranched polymer $\mathbf{6}$ with an approximately $100 \%$ DB, which was determined from the ${ }^{13} \mathrm{C}$ NMR spectrum of $\mathbf{6}$. 
Acknowledgment. This work was supported by Grants-in-Aid for Scientific Researches (No. 19655040) from the Ministry of Education, Science, Sports and Culture of Japan.

\section{REFERENCES}

1. G. R. Newkome, C. N. Moorefield, and F. Vogtle, in "Dendrimers and Dendrons," Wiley-VCH, New York, 2001, p 331.

2. M. Jikei and M. Kakimoto, Prog. Polym. Sci., 26 (2001).

3. Y. H. Kim, J. Polym. Sci., Part A: Polym. Chem., 36, 1685 (1998).

4. C. Gao and D. Yan, Prog. Polym. Sci., 29, 183 (2004).

5. B. J. Voit, J. Polym. Sci., Part A: Polym. Chem., 43, 2679 (2005).

6. L.-M. Tang, Y. Fang, and J. Feng, Polym. J., 37, 225 (2005).

7. T. Sato, K. Nomura, T. Hirano, and M. Seno, Polym. J., 38, 240 (2006).

8. T. Nishikubo, H. Kudo, K. Maruyama, T. Nakagami, and H. Miyabe, Polym. J., 38, 447 (2006).
9. P. J. Flory, in "Principles of Polymer Chemistry" Cornell University Press, Ithaca, 1953.

10. D. Holter and H. Frey, Polym. Mater. Sci. Eng., 77, 165 (1977).

11. H. R. Kricheldorf, O. Stober, and D. Lubbers, Macromolecules, 28, 2118 (1995).

12. C. J. Hawkwer and F. Chu, Macromolecules, 29, 4370 (1996).

13. L. J. Hobson and W. Feast, Chem. Commun., 2067 (1997).

14. D. Holter and H. Frey, Acta. Polym., 48, 298 (1997).

15. G. Maier, C. Zech, B. Voit, and H. Komber, Macromol. Chem. Phys., 199, 2655 (1998).

16. M. Smet, E. H. Schacht, and W. Dehaen, Angew. Chem. Int. Ed., 41, 4547 (2002).

17. Y. Fu, A. Vandendriessche, V. Dehaen, and M. Smet, Macromolecules, 39, 5183 (2006).

18. P. W. Morgan, Macrmolecules, 3, 536 (1970).

19. M. Yamada, J. Sun, Y. Suda, and T. Nakaya, Chem. Lett., 27, 1055 (1998).

20. R. N. Goerner, Jr., P. N. Cote, and B. M. Vittimberga, J. Org. Chem., 42, 19 (1977). 